\title{
Modern Kontrol Yöntemleri ile Bulanık Mantık Temelli Oda Sicaklık Kontrolü
}

\author{
Mustafa Fatih TOSUN'1 (D), Ahmed Aycan GENÇKAL ${ }^{2}$ (D), Ramazan ŞENOL ${ }^{* 3}$ (D) \\ 1,2,3Isparta Uygulamalı Bilimler Üniversitesi, Teknoloji Fakültesi, Elektrik-Elektronik Mühendisliği Bölümü, \\ Isparta, Türkiye
}

(Alınıș / Received: 19.06.2019, Kabul / Accepted: 16.11.2019, Online Yayınlanma / Published Online: 30.12.2019)

Anahtar Kelimeler

Bulanık mantık,

STM32F4,

Waijung blokları
Özet: Bu çalışmada, bilgisayar ortamında Waijung blok setleri ve STM32F4 Mikrodenetleyicisi kullanılarak oda sıcaklığının kontrolünün gerçekleştirilmesi için simülasyon yapılmıştır. LM35 sıcaklık sensörü ile alınan anlık değerler neticesinde, simulasyon içerisinde hazırlanan bulanık mantık sistemi ile değerlendirilerek gerektiği taktirde fanların ısıtma ya da soğutma yapmasına karar veren oda sıcaklık kontrolü çalışması yapılmıştır. Bunun için bilgisayar ortamında yazlımsal olarak waijung setlerinden, kontrolör olarak da STM32F4 Mikrodenetleyicisinden faydalanılmıştır.

\section{Fuzzy Logic Based Room Temperature Control with Modern Control Methods}

Keywords

Fuzzy logic,

STM32F4,

Waijung

\begin{abstract}
In this study, simulation was performed to control room temperature by using Waijung block sets and STM32F4 Microcontroller in computer environment. As a result of the instantaneous values obtained with the LM35 temperature sensor, the room temperature control study, which decided to heat or cool the fans, was carried out by evaluating with fuzzy logic system prepared in the simulation. For this purpose, waijung sets were used in software and STM32F4 microcontroller was used as controller.
\end{abstract}

\section{Giriş}

Uygulanmakta olan yöntemler göz önüne alındığında, bir odanın sıcaklığını istenilen sabit bir sıcaklıkta tutmak için harcanan enerji miktarı oldukça fazladır. Oda sıcaklığını istenilen sıcaklık değerine getirmek amacıyla kullanılan kontrol yöntemleri çeşitlilikler göstermektedir. Oda sıcaklığının istenilen değerden farklı olması durumunda sistemin tekrar dengeye gelebilmesi için ısıtma elemanının harcayacağı enerjinin optimize edilmesi gerekir. Bu çalışmada bulanık mantık sistemi ile oda sıcaklığını belirlenen değerde sabit olarak tutabilmek için STM32F4 mikrodenetleyici kartına yazılan kural tablosuna göre çıkarım yapılarak sistemin harcayacağı enerji miktarı azaltılmaya çalışılacaktır. PWM ile fan kontrolü yaparak ısıtma soğutma ihtiyacını karşılayacak şekilde optimum enerji tüketimini gerçekleştirecektir. Bilgisayar ortamında simülasyon programında Waijung blok setleri ve bulanık mantık blokları kullanılarak oluşturulan kontrol yapısının STM32F4 denetleyicisine aktarilması ve bu denetleyicinin oda sıcaklığı için gerekli olan algoritmayı sıcaklık sensöründen alınan anlık değerlere göre hazırlaması sağlanmıștır. Bulanık mantık sistemi ile değerlendirilerek gerektiği taktirde fanların ısıtma ya da soğutma yapmasına karar veren oda sıcaklık kontrolü çalışması enerji tasarrufu sağlayacaktır. Literatür taramasında, bulanık mantık kullanılarak oda sıcaklık kontrolünde çeșitli uygulamalar göze çarpmaktadır. Das vd.'nin çalışmasında bulanık teoriye dayalı bir odanın sıcaklık ve nem kontrolü yapılmıştır. Odayı ısıtmak veya soğutmak için fan farklı yönlerde çalıştırılmaktadır. Odanın ideal sıcaklığı 18 ile 26 derece arasında ayarlanmıştır. Odanın sıcaklığı ve hata değeri 7 farklı kademede tanımlanmıştır. Isıtma fan hızı 4 kademe, soğutma fan hızı ise 5 kademe olarak belirlenmiștir. Bulanık mantık yönteminde çıkarım tekniği olarak "Mamdani" yöntemi kullanılmıştır [1]. Etik, yüksek lisans tezinde bir ameliyathanenin en uygun çalışma konforunun sağlanmasını amaçlamıştır. Bunun için ameliyathanenin sıcaklık, nem, oksijen ve partikül değerlerini ölçerek bulanık mantık yöntemiyle klimanın hızını ve egzoz fanının devir sayısını kontrol etmektedir [2]. Singhala vd. 2014 yılında yaptıkları çalışmada mikrodenetleyici kullanarak bulanık mantık temelli sıcaklık kontrolü uygulaması gerçekleştirmişlerdir [3]. Ayan ve Şenol, yapmış 
oldukları çalışma da bulanık mantık temelli PLC tarafindan kontrol edilen, 3G ile uzaktan kontrol edilebilen bir sera otomasyonu gerçekleștirilmiştir [4]. Li vd. PLC temelli akıllı bir sera kontrol sistemi ile bitkilerin ihtiyaç duyacakları sıcaklık, nem ve ışık miktarlarını karşılayacak şekilde bir sistem tasarlamışlardır [5]. Revathi ve Sivakumaran sera içerisindeki sıcaklığı ölçmekte ve akıllı kontrol cihazları kullanarak, sera temel hacminin enerji dengesine bağlı olarak ısıtma gücünü hesaplamaktadır [6]. Alpay, yüksek lisans çalışmasında seraların sıcaklık, bağll nem, toprak nemi ve ışık yoğunluğu gibi çevresel parametrelerini gerçek zamanlı olarak izlenmesi için bulanık mantık temelli sera sistemi geliştirmiştir [7]. Önerilen çalışmada ise literatürde mevcut olmayan bir yöntem ele alınmıștır. Burada işlemci olarak STM32F4 kullanılmış ve kontrol tekniği için yazılımsal olarak Waijung bloklarından yararlanılmıştır. Önerilen çalışmada kullanılan ekipman ve yöntemler hem güvenilir çalışma hem de ekonomik çözüm sunması açısından öne çıkmaktadır.

\section{Materyal ve Metot}

\subsection{Bulanık mantık (Fuzzy logic)}

1965 yılında Azeri asıllı Lotfi A. Zadeh tarafından geliştirilen bulanık mantık [fuzzy logic] kuramı, iki değerli mantık kuramlarına bir alternatif oluşturmuş, sibernetik ve onunla doğrudan ilgili bilimlerde akıl almaz derecede hızlı gelişmeleri tetiklemiş, sibernetik ve yapay zekâ çalışmalarını hızlandırmıştır [8]. Bulanık mantık temelli kontrolörler çıkış değerlerinin hesaplanması için insan beyninin karar verme mekanizmasını taklit eden kural tabanlı bir sonuç çıkarım sistemine sahiptir. Sicaklık gibi ortam parametrelerinin düzenlenmesi amacıyla bulanık gömülü kontrolör kullanılması ısitma ve havalandırmaya yönelik enerji tüketimini minimuma düşürmek için oldukça güçlü bir yaklaşım sağlar [9]. Bulanık Mantık günlük yaşantımızda kullandığımız ve davranışlarımızı yorumladığımız yapıya ulaştıran matematiksel bir disiplindir. Bulanık Mantık kavramlarını yaşantımızın birçok yerinde görmekteyiz. Bu kavramlar yüksek, orta ve düşük değerlerdir. Bunun yanında; çok düşük, orta ve çok yüksek gibi ara değerleri de içerir. Bulanık Mantığın temelini bulanık küme olușturmaktadır. Bulanık kümeler bulanık sistemlerin en temel konusudur. Klasik küme yaklaşımında elemanlar ya o kümeye aittir (1) ya da değildirler (0). Oysa Bulanık Mantık yaklaşımında ise elemanların o kümeye aitliği 0 ile 1 arasında değişir. Herhangi bir sıcaklık derecesi klasik kümeye göre ya sıcak olabilir ya da sıcak olmayabilir. Bulanık kümeye göre bu sıcaklık ait olduğu kümede

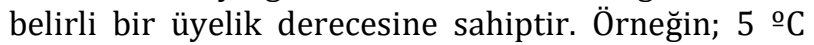
sıcaklık değeri çok düșük kümesine göre 0.5 üyelik derecesi ile düşük kümesi ise 0.667 üyelik derecesi ile ait olabilir [10]. Bulanık mantık denetleyici sistemlerde ilk olarak ne yapılacağına karar vermek daha sonra bulanık mantık kural tablosunu çıkarmak gerekmektedir. Bu kurallar sonucunda sistem kontrol edilir [11]. Bulanık mantık çalışma durumu kurallardan oluşan çıkarımlar sistemi olarak ele alınabilir [12].

\subsection{Simulasyon ortamı}

Simulasyon ortamı bize kompleks sistemleri dizayn etme ve gerçek zamanlı sonuçlara ulaşma imkanı vermektedir. Sistem tasarımında büyük ölçüde bilgisayar ortamından yararlanılmakta, gerektiğinde sistemin test adımları da bilgisayarlar ile yapılmaktadır. Simülasyon ortamı analog ve dijital sistemleri ya da ikisini de kapsayan sistemleri destekleyebilmektedir. Simülasyon ortamına waijung bloklarının dahil edilmesiyle bulanık mantık işlemlerinin STM32 denetleyicisi içerisinde kullanım imkanı doğmaktadır.

\subsection{STM32F4 ve Waijung blok seti}

STM32F4 ARM tabanlı olup yüksek performans sergiler. Bilgisayar ortamında Waijung blok setleri ve diğer bloklar ile kolayca programlanabilmektedir. Kart üzerinde bulunan TX ve RX pinleri ile ve mini USB girişi sayesinde bilgisayar veya çevre birimler ile haberleștirilmektedir. Kartın üzerinde toplam 100 adet pin bulunmaktadır. Üzerindeki sarı, kırmızı, yeşil, turuncu renkli ledler sayesinde kullanıcılar projelerinin anlık durumlarını kolaylıkla kontrol edebilmektedir. Bunun yanında kart üzerinde reset butonu ve kullanıcı butonu bulunmaktadır. Bilgisayar ortamında waijung blok setler kullanıcılara birçok kolaylık sağlar. STM32F4'e ait genel görüntü ve bağlantı uçları şekil 1'de görülmektedir.

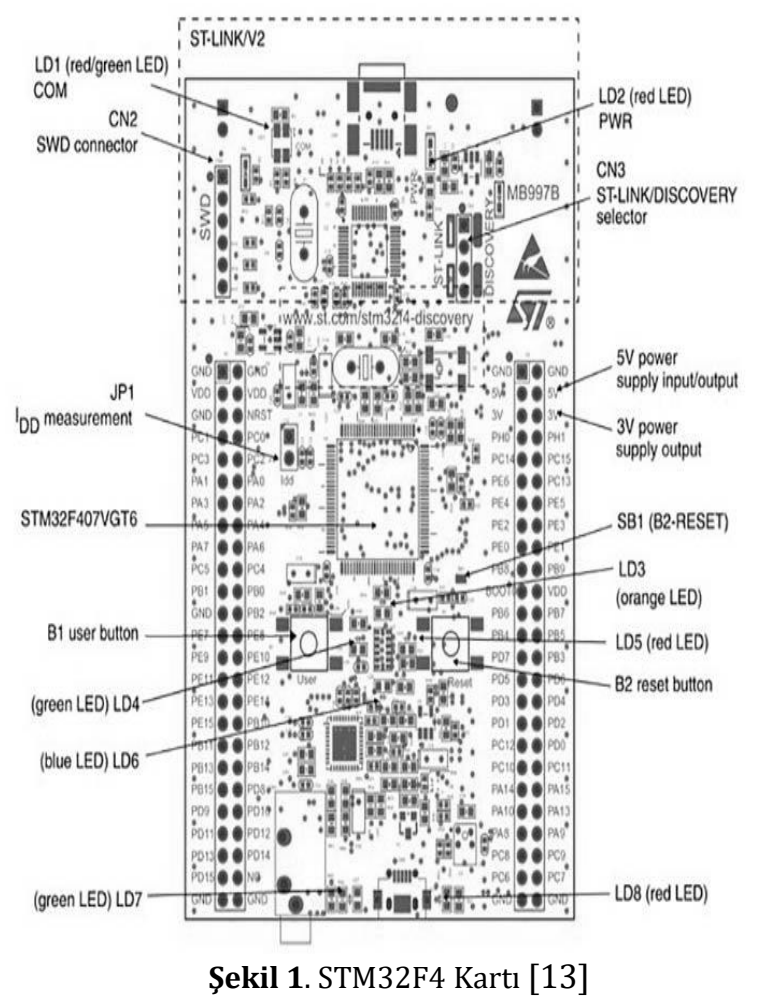

Şekil 1. STM32F4 Kartı [13] 
Waijung blok seti Tayvanlı bir firma tarafından geliștirilmiş ve kullanıcılara simülasyon ortamında uygulama geliştirme imkânı veren blok set tabanlı çalışan bir yapıya sahiptir. "ToolBox" ve "BlockSet" uygulamaları elektronik devrelerin gerçekleștirilmesine yardımcı olur. STM32F4 kiti ve Waijung BlockSet ile gerçekleştirilebilecek uygulamalardan bazıları ve bu uygulamalarda kullanılan bloklar Tablo 1'de görülmektedir.

Bilgisayardan STM32F4'e veri göndermek için gerekli olan sürücülerin bilgisayara yüklenmelidir. Bilgisayar ile STM32F4 haberleşmek için USB-UART dönüştürücüsüne ihtiyaç duymaktadır. Terminal programlarından biri olan Docklight programı ile de bu haberleşme gözlemlenebilmektedir.

\subsection{Akış diyagramı ve bağlantı şeması}

Odanın sıcaklığını algılamak için LM35 sıcaklık sensörü kullanılmıştır. Set edilen oda sıcaklığına ulaşılıp ulaşılmadığı, ısıtma modu veya soğutma modu çalışma durumu bulanık mantık temelli olarak STM32 tarafından icra edilmektedir. Hata değeri ise odanın olmasını istediğimiz sıcaklık ile sensörden okunan sıcaklık değeri arasındaki fark olarak ifade edilir. Bu iki bilgi girmiş olduğumuz bulanık mantık kurallarına göre değerlendirilip durulaştırma işlemi gerçekleştirilmektedir. Durulaştırma işleminden sonra çıkıştaki anlamlı bilgiyi ortam koşullandırıcı ünitenin soğuk ve sıcak kısımlarını kontrol etmek amacıyla sürücü üniteye aktarılmaktadır (Şekil 2). Şekil 3'te sıcaklık sensörü ve FT232 USB-UART dönüștürücünün bağlantısı görülmektedir. LM35 sıcaklık sensörü $-55^{\circ} \mathrm{C}$ ile $150^{\circ} \mathrm{C}$ arasında ölçüm yapabilmektedir [14].

Negatif sıcaklık değerlerini görebilmek için şekil 3'teki gibi bir bağlantı ve tablo 2'de verilen sensör değerlerinden yararlanılmıştır. STM32'nin PA5 bacağından pozitif sicaklık değerlerinin PA6 bacağından ise negatif sıcaklık değerlerinin algılanması yapılmıștır. Çıkış gerilimi Vout=(PA5PA6)*(3300/4095) ifadesi ile bulunur. Ft232 USBUART dönüştürücü STM32 ile bilgisayarın haberleşme işlemini yapmaktadır.

Ft232'nin TX bacağı STM32'nin D9 bacağına; RX bacağı ise D8 bacağına bağlanmaktadır. Ortamdaki her bir derecelik değişim için LM35 sıcaklık sensörü çıkış bacağından analog olarak $1^{\circ} \mathrm{C}$ için $10 \mathrm{mV}$ gerilim üretmektedir. Docklight iki seri cihaz arasında iletişimi izlemek için ya da tek bir cihazın seri haberleşmesini test etmek için kullanılan bir yazılımdır. Docklight ile seri protokol simülasyonu, RS232 veri günlüğü, belirli veri dizileri algılama ve gelen verilere tepki uygulamaları yapılabilir. Şekil 4'te denemeler esnasında alınan sıcaklık verileri, ısıtma ve soğutma çalışma durumlarına ait veriler görülmektedir.

Tablo 1. STM32F4 kiti ile Waijung blok seti kullanarak gerçekleștirilebilecek örnekler

\begin{tabular}{|l|l|}
\hline Uygulama Adı & Kullanılacak Waijung Blokları \\
\hline Buton kontrollü Led yakıp söndürme & Digital Input, digital output \\
\hline Sıcaklık sensörü kullanılarak adc uygulaması & Regular adc \\
\hline Seri porttan bilgisayara veri gönderme ve alma & Uart setup, uart rx, uart tx \\
\hline Dc motor yön ve pozisyon bilgilerinin elde edilmesi & Encoder read, uart tx \\
\hline
\end{tabular}

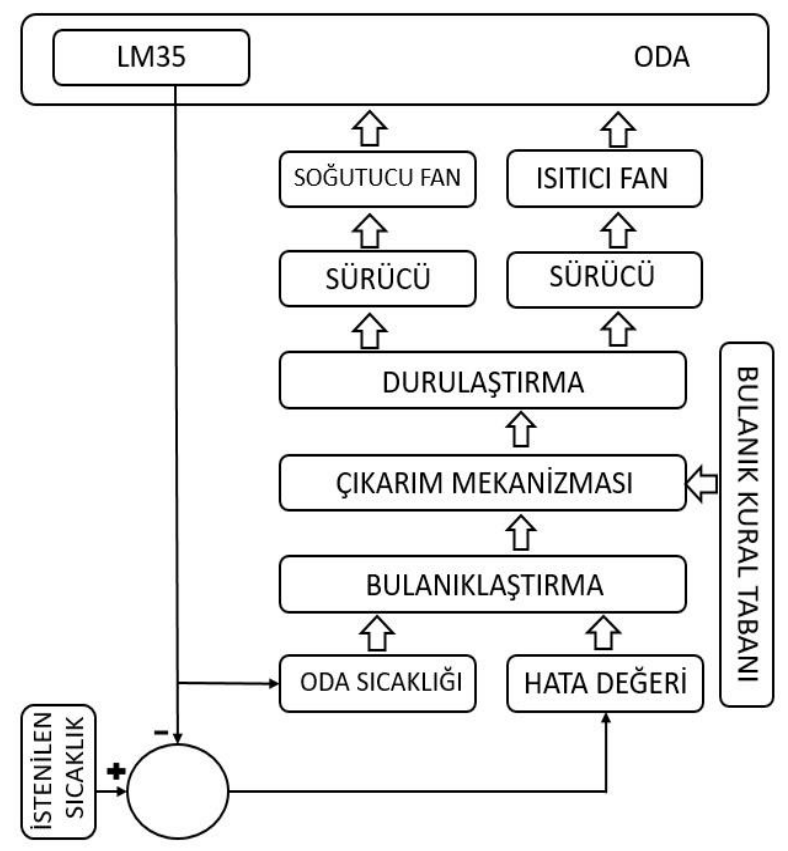

Şekil 2. Blok diyagramı 


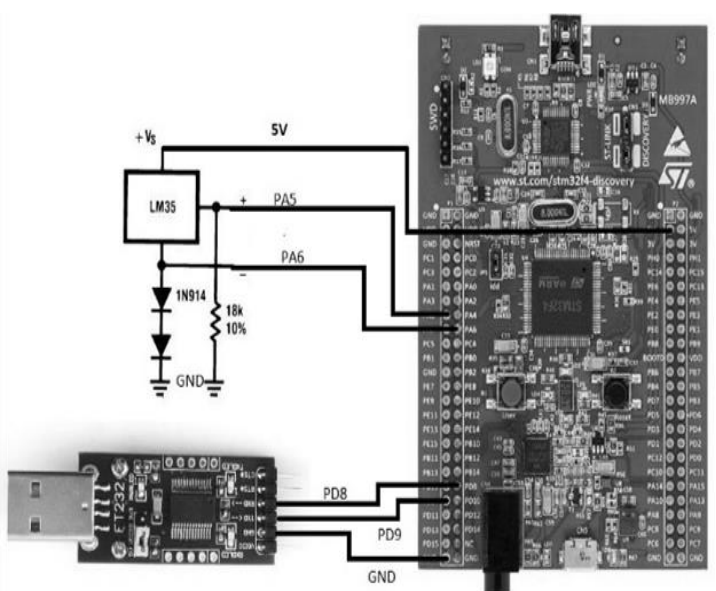

Şekil 3. Projenin bağlantı șeması

Tablo 2. LM35 Ölçüm Aralı̆̆g [14]

\begin{tabular}{|c|c|c|}
\hline & Vout & Sicaklık (derece) \\
\hline 1. & $1500 \mathrm{mV}$ & $150^{\circ} \mathrm{C}$ \\
\hline 2. & $250 \mathrm{mV}$ & $25^{\circ} \mathrm{C}$ \\
\hline 3. & $-550 \mathrm{mV}$ & $-55^{\circ} \mathrm{C}$ \\
\hline
\end{tabular}

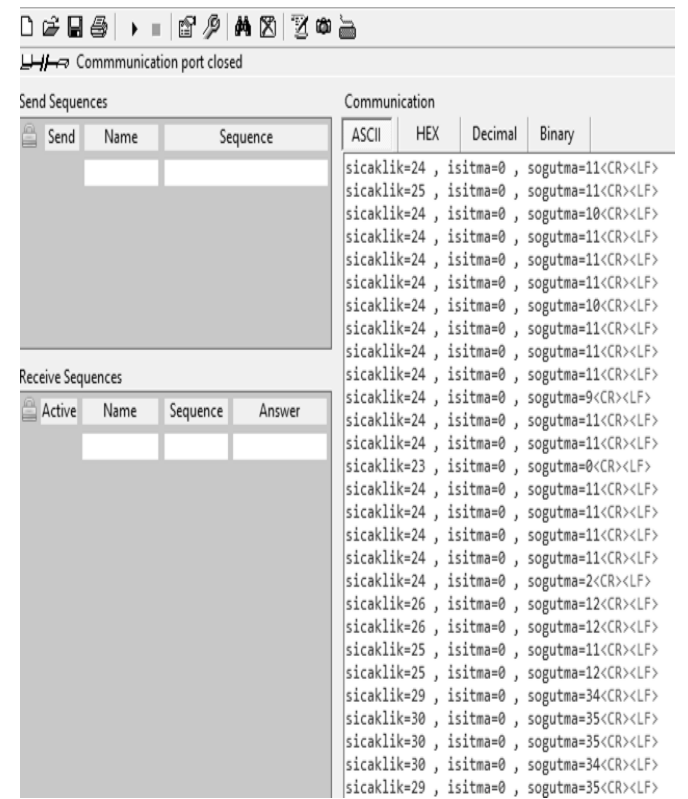

Şekil 4. Elde edilen verilerin bilgisayar ekranında izlenmesi

\subsection{Simülasyon ve Waijung blokları}

Bilgisayar ortamında Waijung blok diyagramında odanın sıcaklığını istenilen sıcaklıkta tutmak için iklimlendirici ünite kontrol edilmektedir. Sistem tasarımı $0^{\circ} \mathrm{C}$ ile $38^{\circ} \mathrm{C}$ arasında çalışma durumuna göre yapılmıștır. Tasarımda kullanılan blok setler aşağıda kısaca tanıtılmıştır.

\subsubsection{Waijung Target Setup bloğu}

STM32F4 kitinde uygulama geliştirmek için simülasyon ortamına Waijung blockset içerisindeki STM32F4 Target bloğunun eklenmesi (Şekil 5) gerekmektedir. Target setup bloğu geliştirilen uygulamayı STM32F4 için kod satırlarına dönüştürülmesi ve derlenmesi işlemlerini yapmaktadır. Derleme işleminin gerçekleşmesi için bu blok Waijung blok setleri ile oluşturulan her uygulamada olmak zorundadır [15].

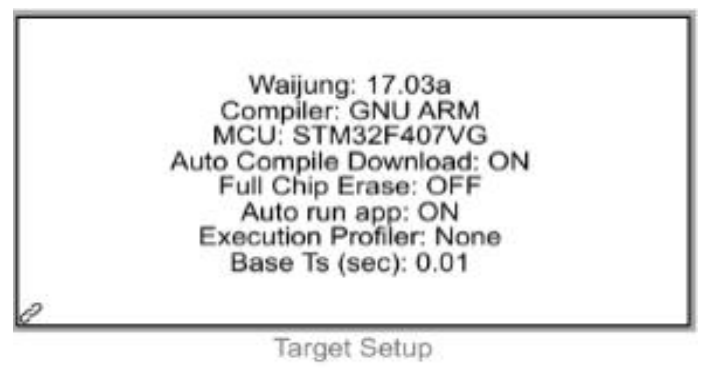

Şekil 5.Waijung target setup bloğu

\subsubsection{Analog Digital Converter (ADC) bloğu}

Dış ortamdan elde edilen analog verilerin okunup dijital verilere dönüştürülmesi için şekil 6'da görülen waijung ADC modülü kullanılır.

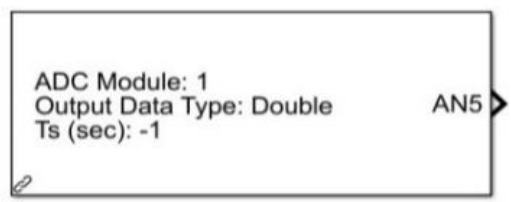

Şekil 6. Analog dijital dönüștürücü (ADC) bloğu.

\subsubsection{PWM bloğu}

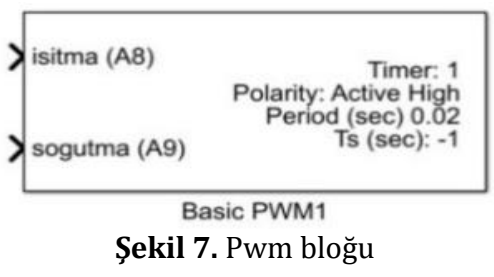

İklimlendirici ünitedeki fanların hızı pwm sinyalleri ile ayarlanmaktadır. Fuzzy bloğunun çıkışından elde edilen veri ısıtma ve soğutma olmak üzere iki adet pwm sinyaline dönüştürülmektedir.

\subsubsection{UART bloğu}

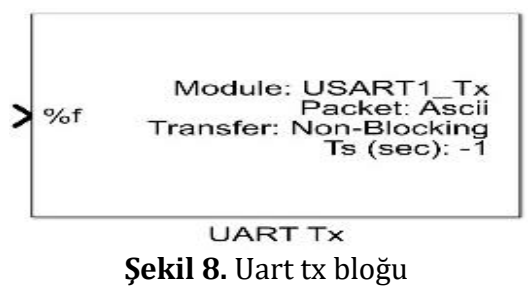

UART bloğu STM32 ile bilgisayarın haberleşmesi için eklenmiştir. Odanın sıcaklığı ile ısıtma ve soğutma değerlerini docklight programı sayesinde anlık olarak bilgisayar ekranından da izleyebilmek ve sistemin ön testlerini yapabilmek amacıyla kullanılmıştır.

\subsubsection{Fuzzy bloğu}

Bulanık mantık yöntemiyle girişlerden elde edilen verileri değerlendirerek karar veren blok yapısı şekil 9'da görülmektedir. Şekil 10'da ise sistemin hazırlanan simülasyonu ve STM32 kitine yüklenen hali görülmektedir. 


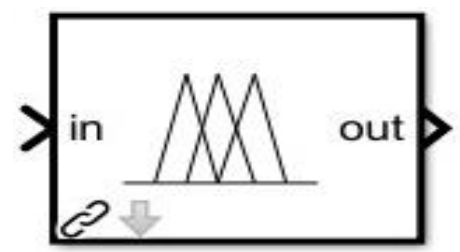

Şekil 9. Fuzzy bloğu

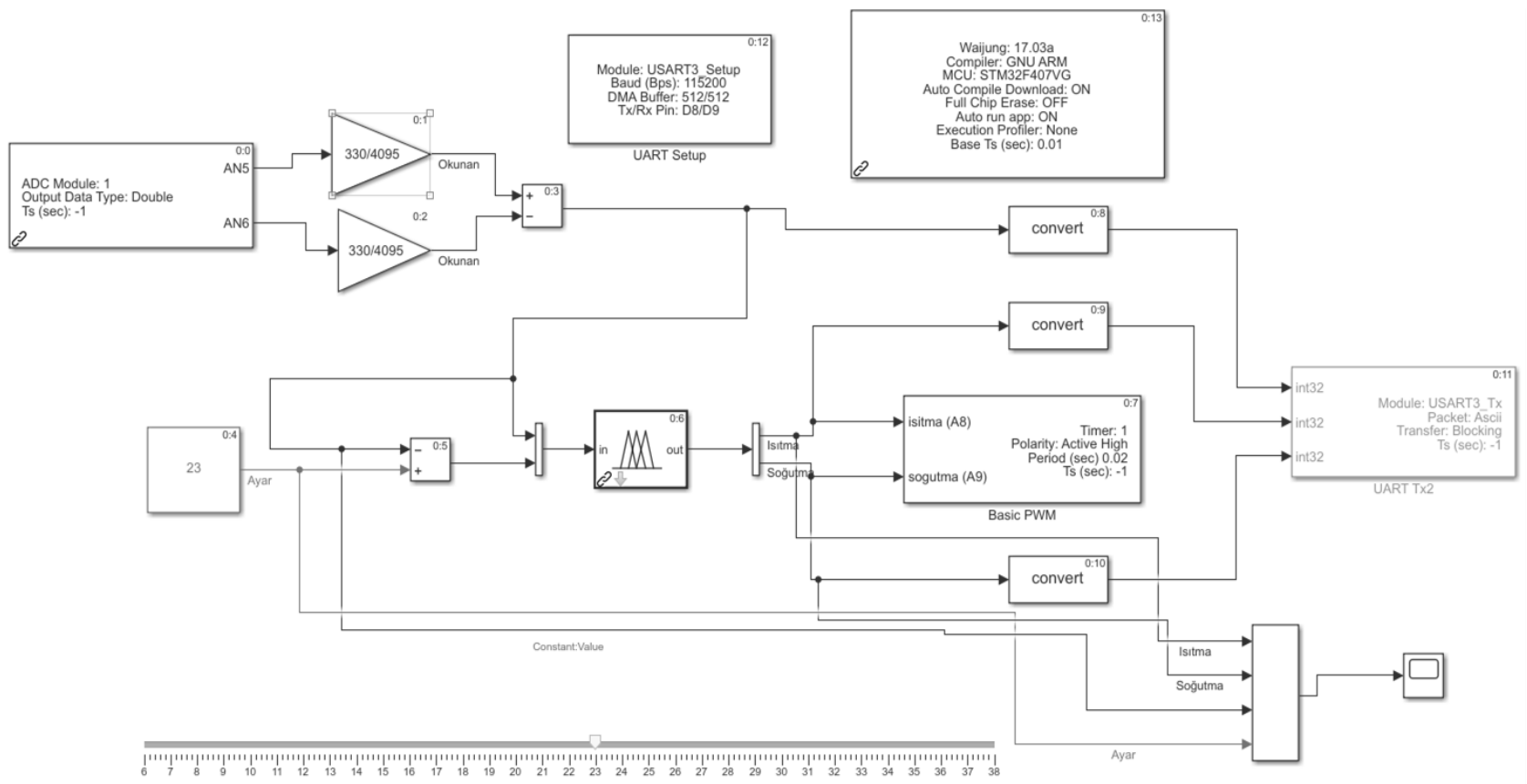

Şekil 10. STM32 içerisine aktarılan bloklar

\subsection{Giriş üyelik fonksiyonları}

Odada bulunan sıcaklık sensörü tarafından odanın o anki okunan sıcaklığı giriș olarak alınmıștır. Odanın mevcut sıcaklığı soğuk, serin, ılık, sıcak ve çok sıcak olmak 5 gruba ayrılmıştır. Bu aralıklar odanın sıcaklık üyelik fonksiyonlarını vermektedir.

Tablo 3.Odanın sıcaklık üyelik fonksiyonu

\begin{tabular}{|l|l|}
\hline SICAKLIK FONKSIYONU & SICAKLIK ARALIKLARI \\
\hline SOĞUK & 0 ile 14 \\
\hline SERIN & 12 ile 20 \\
\hline ILIK & 18 ile 26 \\
\hline SICAK & 24 ile 32 \\
\hline ÇOK SICAK & 30 ile 38 \\
\hline
\end{tabular}

Simülasyon ortamında hazırlanan bulanık mantık sistemi genel yapısı görülmektedir.

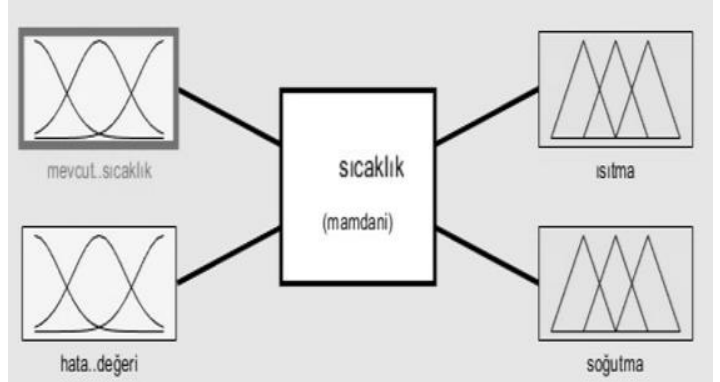

Şekil 11. Bulanık mantık giriș ve çıkışları

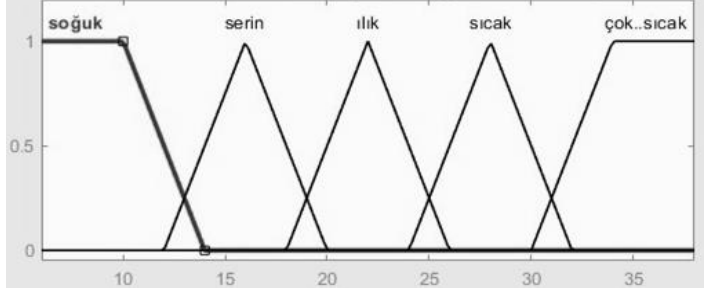

Şekil 12. Mevcut sıcaklık üyelik fonksiyonu

Mevcut sıcaklık üyelik fonksiyonu bulunurken trimf (üçgen) yöntemi kullanılmaktadır. Giriş için kullanılan hata değeri odanın sıcaklığının istenilen sıcaklıktan sapma değeri olarak ifade edilebilir. Odanın sıcaklığı $0^{\circ} \mathrm{C}$ ile $38^{\circ} \mathrm{C}$ arasında olabilmektedir. Odanın sıcaklığı ise istenilen sıcaklıkta ayarlanabilmektedir. Odanın mevcut sıcaklı̆̆ının istenilen sıcaklığa olan uzaklı̆̆ hata değeri olarak adlandırılmaktadır. 9 adet hata üyelik fonksiyonu bulunmaktadır. Hata değeri üyelik fonksiyonu bulunurken trimf (üçgen) yöntemi kullanılmaktadır.

Tablo 4. Odanın hata üyelik fonksiyonları

\begin{tabular}{|l|l|}
\hline HATA FONKSIYONU & HATANIN UZAKLIĞI [C] \\
\hline NHÇY & -18 ile -11 \\
\hline NHY & -13 ile -8 \\
\hline NHO & -10 ile -4 \\
\hline NHD & -6 ile -1 \\
\hline İSTENEN HATA & -3 ile 3 \\
\hline PHD & 1 ile 6 \\
\hline PHO & 4 ile 9 \\
\hline PHY & 7 ile 12 \\
\hline PHÇY & 10 ile 18 \\
\hline
\end{tabular}




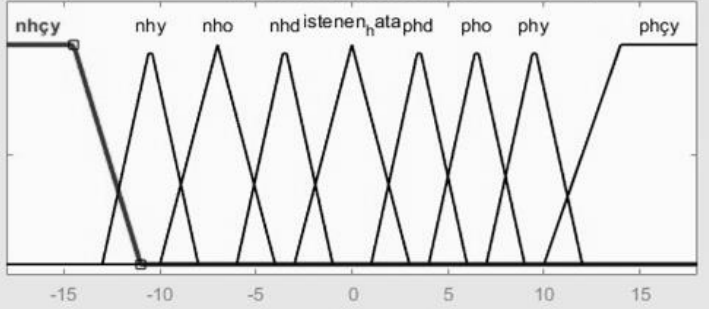

Şekil 13. Hata değeri üyelik fonksiyon grafiği

\section{7. Çıkış üyelik fonksiyonları}

Isıtma fan hızı, odayı ısıtmak için kullanılacak olan fanın dönme hızıdır. Fanın hızı yüz üzerinden değerlendirilmektedir. Fan hızı dur, yavaş, orta, hızlı ve çok hızlı olmak üzere 5 adet üyelik grubuna ayrılmıştır.

Tablo 5. Odayı ısıtmak için fanın çalışma hızı üyelik fonksiyonu

\begin{tabular}{|l|l|}
\hline ISITMA FAN FONKSIYONU & FAN HIZI ARLIKLARI \\
\hline IFD - DUR & 0 \\
\hline IFY - YAVAȘ & 0 ile 25 \\
\hline IFO - ORTA & 20 ile 50 \\
\hline IFH - HIZLI & 45 ile 75 \\
\hline IFÇH - ÇOK HIZLI & 75 ile 100 \\
\hline
\end{tabular}

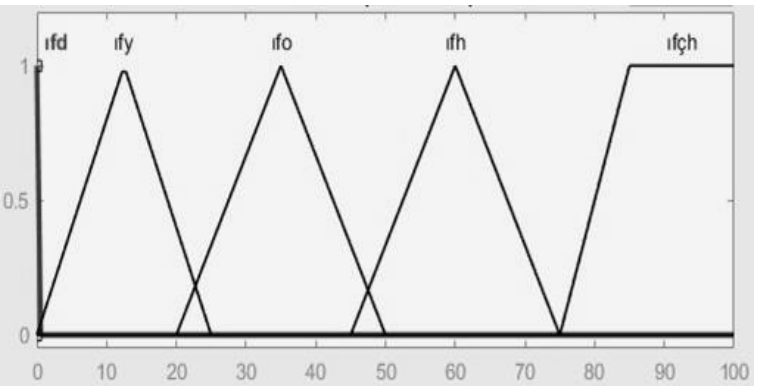

Şekil 14. Isıtma fan hızı üyelik fonksiyonları

Odayı soğutmak için kullanılan fanın hızı ise soğutma fan hızıdır. Fanın hızı yüz üzerinden değerlendirilmektedir. Dur, yavaş, orta, hızlı ve çok hızlı olmak üzere 5 kademeye ayrılmaktadır.

Tablo 6. Odayı soğutmak için fanın çalışma hızı üyelik fonksiyonu

\begin{tabular}{|l|l|}
\hline SOĞUTMA FAN FONKSIYONU & FAN HIZI ARLIKLARI \\
\hline SFD - DUR & 0 \\
\hline SFY - YAVAȘ & 0 ile 25 \\
\hline SFO - ORTA & 20 ile 50 \\
\hline SFH - HIZLI & 45 ile 75 \\
\hline SFÇH - CCOK HIZLI & 75 ile 100 \\
\hline
\end{tabular}

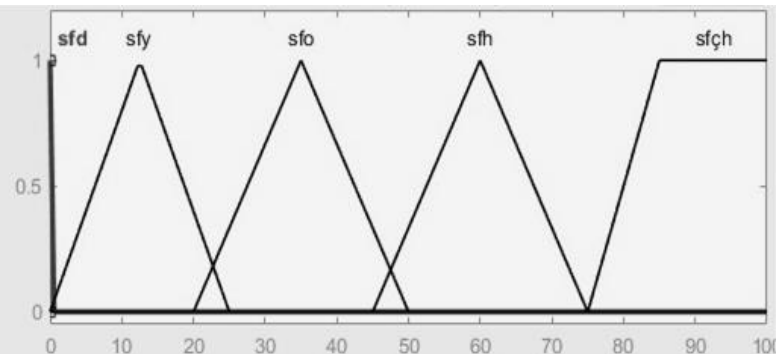

Şekil 15. Soğutma fan hızı üyelik fonksiyonu grafiği

\subsection{Kural tablosu ve durulaştırma}

Sistemi bulanıklaştırdıktan sonra kural tablosu olușturulmaktadır. Bulanık sistem kural tablosuna göre bir çıkıș üretecek; bu çıkıșa durulaștırma ișlemi uygulanacaktır. $\mathrm{Bu}$ sistemde 45 adet kural bulunmaktadır. Durulaştırma neticesinde ısıtma ve soğutma fan hızları kontrol edilmektedir. Girişteki sıcaklık ve hata değerine göre 0 ile 100 arasında değer üretmektedir. Bu değerleri basit PWM bloğuna göndermektedir. Durulaştırma yöntemi olarak centroid yöntemi kullanılmıştır.

Tablo 7. Bulanık mantık üyelik fonksiyonları kural tablosu

\begin{tabular}{|c|c|c|c|c|}
\hline $\begin{array}{l}\text { KURAL } \\
\text { NO }\end{array}$ & $\begin{array}{l}\text { ODANIN } \\
\text { SICAKLIĞI }\end{array}$ & HATA & $\begin{array}{l}\text { ISITMA } \\
\text { FAN }\end{array}$ & $\begin{array}{l}\text { SOĞUTMA } \\
\text { FAN }\end{array}$ \\
\hline 1 & SOĞUK & NHÇY & IFD & SFÇH \\
\hline 2 & SOĞUK & NHY & IFD & SFH \\
\hline 3 & SOĞUK & NHO & IFD & SFO \\
\hline 4 & SOĞUK & NHD & IFD & SFY \\
\hline 5 & SOĞUK & İH & IFD & SFD \\
\hline 6 & SOĞUK & PHD & IFY & SFD \\
\hline 7 & SOĞUK & PHO & IFO & SFD \\
\hline 8 & SOĞUK & PHY & IFH & SFD \\
\hline 9 & SOĞUK & PHÇY & IFÇH & SFD \\
\hline 10 & SERIN & NHÇY & IFD & SFÇH \\
\hline 11 & SERIN & NHY & IFD & SFH \\
\hline 12 & SERIN & $\mathrm{NHO}$ & IFD & SFO \\
\hline 13 & SERIN & NHD & IFD & SFY \\
\hline 14 & SERIN & $\dot{\mathrm{I}} \mathrm{H}$ & IFD & SFD \\
\hline 15 & SERIN & PHD & IFY & SFD \\
\hline 16 & SERIN & $\mathrm{PHO}$ & IFO & SFD \\
\hline 17 & SERIN & PHY & IFH & SFD \\
\hline 18 & SERIN & PHÇY & IFÇH & SFD \\
\hline 19 & ILIK & $\mathrm{NHCSY}$ & IFD & SFÇH \\
\hline 20 & ILIK & NHY & IFD & SFH \\
\hline 21 & ILIK & NHO & IFD & SFO \\
\hline 22 & ILIK & NHD & IFD & SFY \\
\hline 23 & ILIK & $\dot{\mathrm{I}} \mathrm{H}$ & $\begin{array}{l}\text { IFD } \\
\end{array}$ & SFD \\
\hline 24 & ILIK & PHD & IFY & SFD \\
\hline 25 & ILIK & PHO & IFO & SFD \\
\hline 26 & ILIK & PHY & IFH & SFD \\
\hline 27 & ILIK & PHÇY & IFÇH & SFD \\
\hline 28 & SICAK & NHÇY & IFD & SFÇH \\
\hline 29 & SICAK & NHY & IFD & SFH \\
\hline 30 & SICAK & $\mathrm{NHO}$ & IFD & SFO \\
\hline 31 & SICAK & NHD & IFD & SFY \\
\hline 32 & SICAK & İH & IFD & SFD \\
\hline 33 & SICAK & PHD & IFY & SFD \\
\hline 34 & SICAK & PHO & IFO & SFD \\
\hline 35 & SICAK & PHY & IFH & SFD \\
\hline 36 & SICAK & PHÇY & IFÇH & SFD \\
\hline 37 & ÇOK SICAK & NHÇY & IFD & SFÇH \\
\hline 38 & ÇOK SICAK & NHY & IFD & SFH \\
\hline 39 & ÇOK SICAK & $\mathrm{NHO}$ & IFD & SFO \\
\hline 40 & CCOK SICAK & NHD & IFD & SFY \\
\hline 41 & ÇOK SICAK & İH & IFD & SFD \\
\hline 42 & ÇOK SICAK & PHD & IFY & SFD \\
\hline 43 & ÇOK SICAK & $\mathrm{PHO}$ & IFO & SFD \\
\hline 44 & ÇOK SICAK & PHY & IFH & SFD \\
\hline 45 & ÇOK SICAK & PHÇY & IFÇH & SFD \\
\hline
\end{tabular}

\section{Bulgular}

Uygulama bağlantısı şekil $16^{\prime}$ da görülmektedir. STM32, ft232 ve sıcaklık sensörü bağlantısı şekil 3'te gösterildiği gibi yapılmıştır. Şekil 16 'da görülen sistemde STM32 içerisine şekil 10'da gösterilen bloklar aktarılmıștır. Sistemin anlık olarak çıkışları hem bilgisayar ortamında hem de osiloskop ekranında gözlenmiştir. Sistemin harici sinyaller ile test edilmesine ait görüntü șekil 17'de verilmiștir. Test işlemleri için; ayarlanan ortam sıcaklık değerine karşılık ortamdan okunan değer yerine bir sinyal jeneratöründen sinüs işareti giriş olarak alınmıştır. 
Okunan değer, ısıtma çıkış değeri, soğutma çıkış değeri ve ayar değerleri osiloskop ekranında gözlenmiștir.

Sistemin LM35 sensörü ile ortam sıcaklığl kontrolünde kullanımı esnasında elde edilen test görüntüsü ise şekil 21'de verilmiștir.

Şekil 19 ve şekil 20 incelendiğinde tasarlanan sisteme ait simülasyon sonuçları görülmektedir. Sisteme ortam sicaklığ 1 olarak $0^{\circ}$ den başlayarak 20\%'nin üzerine kadar sıcaklık artışı giriş olarak uygulanmış ve sonrasında bu giriş değeri 20 derecenin altındaki ve üzerindeki farklı değerlere değiștirilerek sistemin çalışma modlarının değişimi Şekil 19 da, ısıtma veya soğutma fan hızlarının değişimi ise șekil 20'de verilmiştir.

Şekil 21'de ise gerçekleştirilen sistemin gerçek zamanlı ve oda sıcaklığı şartlarındaki test sonuçları ısıtma modu için gösterilmiştir. Osiloskop görüntüsünde üstteki eğri LM35 üzerine ortamdan uygulanan sıcaklık değişimini göstermektedir. Alttaki eğri ise sistemin ısıtma çıkışını gösterir.

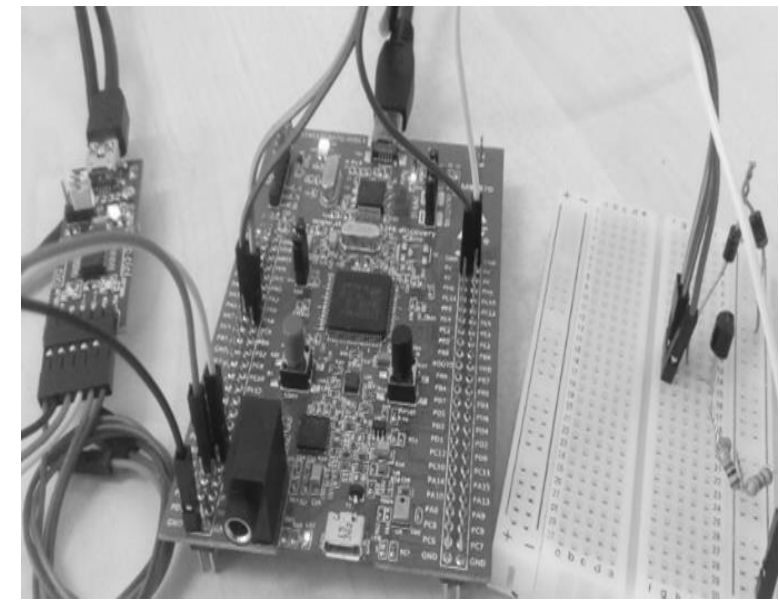

Şekil 16. Uygulama bağlantısı

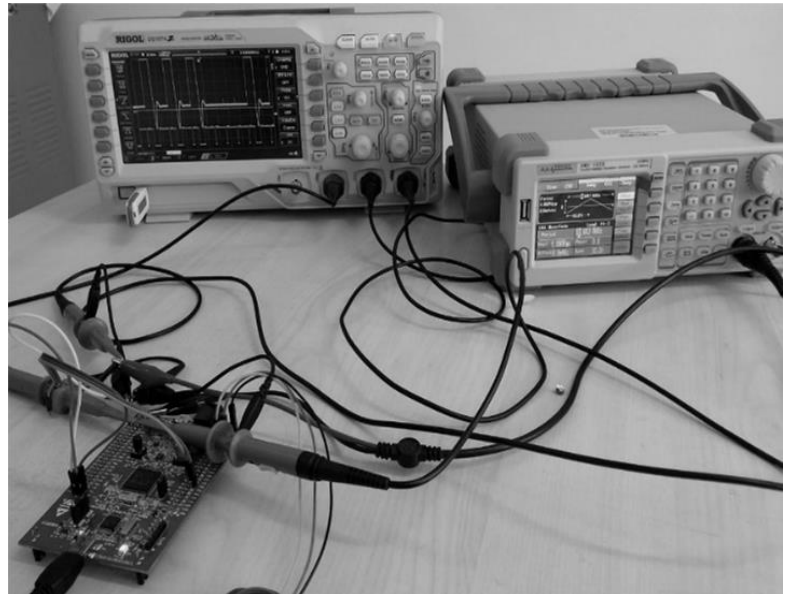

Şekil 17. Sistemin harici sinyaller ile test edilmesine ait görüntü

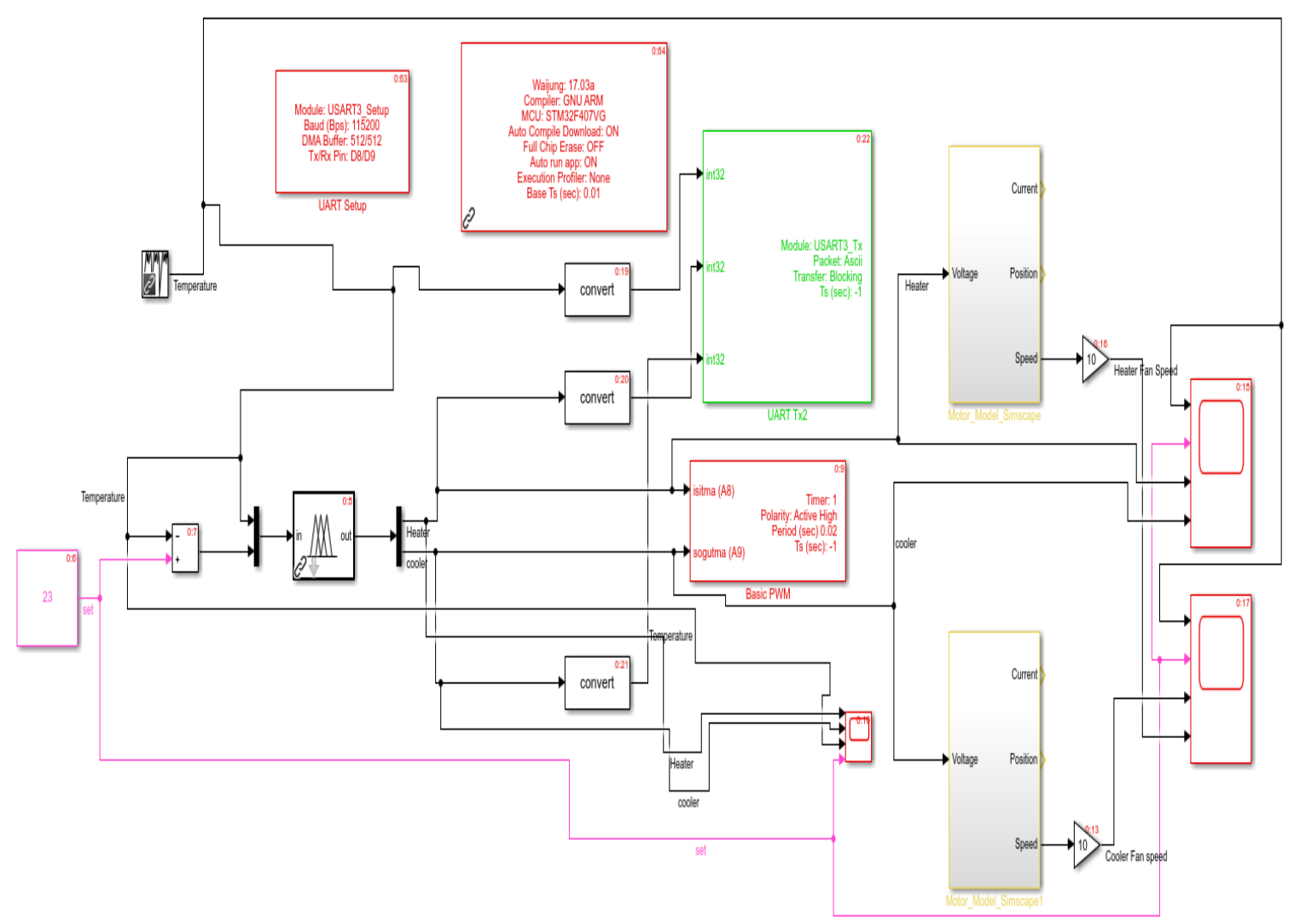

Şekil 18. Uygulama öncesinde bilgisayar ortamında gerçekleștirilen testin blok bağlantıları 


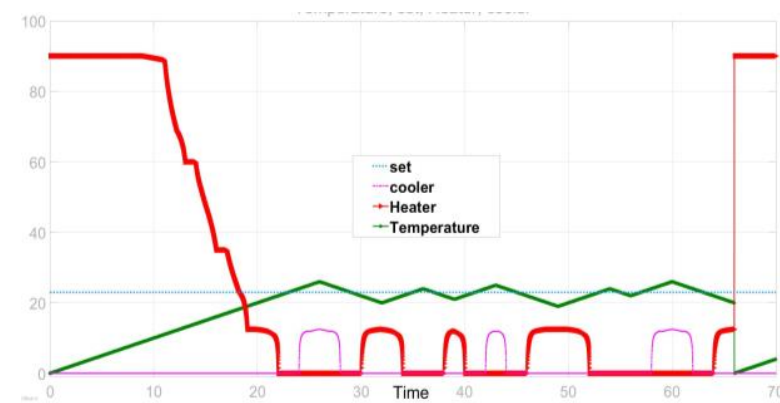

Şekil 19. Uygulama öncesinde bilgisayar ortamında gerçekleştirilen testte elde edilen çalışma modlarının görünümü.

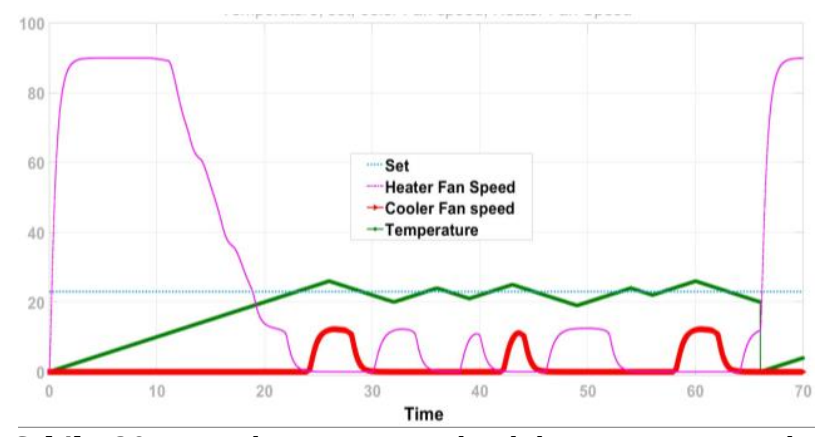

Şekil 20. Uygulama öncesinde bilgisayar ortamında gerçekleștirilen testte elde edilen ısıtma veya soğutma fan hızlarının değişimi

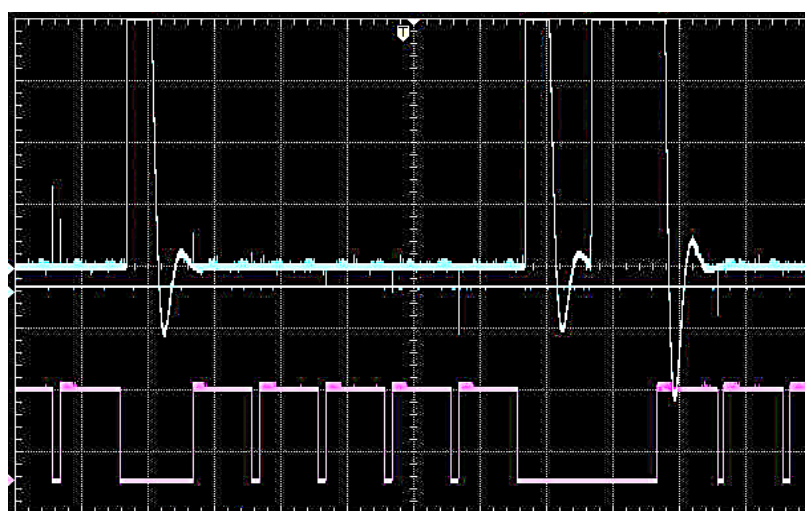

Şekil 21. Sisteme ait gerçek zamanlı test görüntüsü

\section{Tartışma ve Sonuç}

Kurulan simülasyon modeli ile çalışmanın amaçları doğrulanmıştır. Simülasyon modeli ile STM32 içerisine aktarılan bulanık mantık temelli kontrolcünün bir odanın sıcaklık kontrolünde nasıl uygulanabileceği gösterilmiștir. Bir oda için istenilen konfor şartlarının sağlanmasında STM32 ve bulanık mantık kullanımının simülasyon ve uygulama arasındaki elde edilen tutarlılık sonucunda mümkün olacağı görülmüștür.

\section{Kaynakça}

[1] Das, T.K, Das, Y. 2013. Design of A Room Temperature And Humidity Controller Using Fuzzy Logic. American Journal of Engineering Research (AJER), Volume-02, Issue-11, pp-8697.

[2] Etik, N. 2007. Ameliyathane Klima Kontrol Sistemleri İçin Bulanık Uzman Sitem Tasarımı.
Selçuk Üniversitesi, Fen Bilimleri Enstitüsü, Yüksek Lisans Tezi, 62s, Konya.

[3] Singhala, P., Shah, D. N., Patel, B. 2014. Temperature Control using Fuzzy Logic. International Journal of Instrumentation and Control Systems (IJICS) Vol.4, No.1.

[4] Ayan, M., ve Şenol, R. 2016. Bulanık Mantık Tabanl-Uzaktan Erişimli Sera Otomasyonu. Düzce Üniversitesi Bilim ve Teknoloji Dergisi, 4, 734-746.

[5] Li, L., Cheng, K.W.E., and Pan, J.F. 2017. Design and Application of Intelligent Control System for Greenhouse Environment, Power Electronics Systems and Applications - Smart Mobility, Power Transfer \& Security (PESA). 7th International Conference.

[6] Revathi, S., and Sivakumaran, N. 2016. Fuzzy Based Temperature Control of Greenhouse, International Federation of Automatic Control, 49-1: pp.549- 554.

[7] Alpay, Ö. 2018. Sera Uygulamalarında Bulanık Mantık Tabanlı Uzaktan Kontrol Sistemi. Firat Üniversitesi, Fen Bilimleri Enstitüsü, Yüksek Lisans Tezi, 62s, Elazı $\breve{g}$.

[8] Işıklı, Ş. 2008. Bulanık Mantık ve Bulanık Teknolojiler. Ankara Üniversitesi Dil ve TarihCoğrafya Fakültesi Felsefe Bölümü Dergisi Cilt: 19 Sayfa: 105-126.

[9] Ayan, M., Şenol, R. 2016. Bulanık Mantık Tabanlı Uzaktan Erişimli Sera Otomasyonu. Düzce Üniversitesi Bilim ve Teknoloji Dergisi, 4 734746.

[10] Ödük, M., N. 2010. Bulanık Kontrol, Yöntemiyle Sera Otomasyonu. Selçuk Üniversitesi, Fen Bilimleri Enstitüsü, Yüksek Lisans Tezi, 119s, Konya.

[11] Ayan, M. 2015. Bulanık mantık tabanlı-uzaktan erişimli sera otomasyonu. Süleyman Demirel Üniversitesi. Fen Bilimleri Enstitüsü, Yüksek Lisans Tezi, Isparta.

[12] Ayvaz, T. Bulanık Mantık Nedir? https://www.mediaclick.com.tr/blog/bulanikmantik-fuzzy-logic-nedir (Erişim Tarihi: 19.04.2019).

[13] STM32F407VG ürün kataloğu, https://www.st.com/en/microcontrollersmicroprocessors/STM32F407vg.html (Erişim Tarihi: 19.04.2019).

[14] LM35 ürün kataloğu. 2011. http://www.alldatasheet.com/datasheet/pdf/p df/517588/TI1/LM35.html (Erişim Tarihi: 19.04.2019).

[15] Yaren, T., Süel, V., Yeniaydın, Y. 2014. STM32F4 Kiti ile Simulink Tabanlı Kontrol Eğitimi Uygulamaları Geliştirme. TOK Bildiri Kitabı, Kocaeli, 65s. 